\title{
Regulation of Oligodendrocyte Development and Myelination by Glucose and Lactate
}

\author{
Johanne E. Rinholm, ${ }^{1,3}$ Nicola B. Hamilton, ${ }^{1}$ Nicoletta Kessaris, ${ }^{2}$ William D. Richardson, ${ }^{2}$ Linda H. Bergersen, ${ }^{3 *}$ \\ and David Attwell ${ }^{1 *}$ \\ ${ }^{1}$ Department of Neuroscience, Physiology, and Pharmacology, and ${ }^{2}$ Wolfson Institute for Biomedical Research, Department of Cell and Developmental \\ Biology, University College London, London WC1E 6BT, United Kingdom, and ${ }^{3}$ The Brain and Muscle Energy Group, Department of Anatomy and Centre \\ for Molecular Biology and Neuroscience, University of Oslo, N-0317 Oslo, Norway
}

In the gray matter of the brain, astrocytes have been suggested to export lactate (derived from glucose or glycogen) to neurons to power their mitochondria. In the white matter, lactate can support axon function in conditions of energy deprivation, but it is not known whether lactate acts by preserving energy levels in axons or in oligodendrocytes, the myelinating processes of which are damaged rapidly in low energy conditions. Studies of cultured cells suggest that oligodendrocytes are the cell type in the brain that consumes lactate at the highest rate, in part to produce membrane lipids presumably for myelin. Here, we use $\mathrm{pH}$ imaging to show that oligodendrocytes in the white matter of the rat cerebellum and corpus callosum take up lactate via monocarboxylate transporters (MCTs), which we identify as MCT1 by confocal immunofluorescence and electron microscopy. Using cultured slices of developing cerebral cortex from mice in which oligodendrocyte lineage cells express GFP (green fluorescent protein) under the control of the Sox10 promoter, we show that a low glucose concentration reduces the number of oligodendrocyte lineage cells and myelination. Myelination is rescued when exogenous L-lactate is supplied. Thus, lactate can support oligodendrocyte development and myelination. In CNS diseases involving energy deprivation at times of myelination or remyelination, such as periventricular leukomalacia leading to cerebral palsy, stroke, and secondary ischemia after spinal cord injury, lactate transporters in oligodendrocytes may play an important role in minimizing the inhibition of myelination that occurs.

\section{Introduction}

The adult brain normally uses glucose as its primary energy source (Sokoloff, 1992). However, before and immediately after birth, lactate from the blood is also an important energy source (Dombrowski et al., 1989; Vicario et al., 1991; Vicario and Medina, 1992) because the level of glucose in the blood is low at this time, whereas the lactate level is high. Lactate is transported across cell membranes by monocarboxylate transporters (MCTs), of which MCT1-4 cotransport lactate with a proton (Halestrap and Meredith, 2004). In the adult, the supply of lactate from the blood is thought to play a less significant role. However, lactate produced by astrocytes in the gray matter may power neurons in need of extra energy (Pellerin et al., 1998). Similarly, in the white matter, lactate produced by astrocytes can maintain axon function during high neuronal activity or when the glucose supply is limited (Brown et al., 2003, 2004). This effect of lactate has been

Received July 7, 2010; revised 0ct. 17, 2010; accepted 0ct. 27, 2010.

This work was supported by the Steering Board for Molecular Life Sciences at the University of Oslo, the Wellcome Trust, the European Union (Leukotreat), and the European Research Council. We thank Dr. Maz Wilson and Prof. Andrew Halestrap for providing MCT2 and MCT4 antibodies, Palma lanarelli for help with the Sox10-GFP mice, and Prof. Jon Storm-Mathisen for comments on this manuscript.

*L.H.B. and D.A. contributed equally to this work.

Correspondence should be addressed to Linda H. Bergersen, The Brain and Muscle Energy Group, Department of Anatomy and Centre for Molecular Biology and Neuroscience, University of 0slo, N-0317 0slo, Norway. E-mail: 1.h.bergersen@medisin.uio.no.

DOI:10.1523/JNEUROSCI.3516-10.2011

Copyright $\odot 2011$ the authors $\quad 0270-6474 / 11 / 310538-11 \$ 15.00 / 0$ attributed to uptake into axons (Brown et al., 2004; Tekkök et al., 2005), but no direct proof of this has been given and at least some of the lactate may go to preserve the function of the oligodendrocytes that myelinate axons.

Oligodendrocytes develop from oligodendrocyte precursor cells (OPCs), which, during the early postnatal (suckling) period, develop into immature oligodendrocytes and then into mature oligodendrocytes. For myelination to occur, there needs to be sufficient energy available: the oligodendrocytes need to make ATP to maintain cell function and they need carbon skeletons to produce lipids for myelination. Sánchez-Abarca et al. (2001) found that oligodendrocytes in culture consume more lactate than neurons and that the lactate is used not only to fuel the mitochondria but also for lipid synthesis, presumably to make myelin.

Energy deprivation can cause a delay in myelination, or dysmyelination, both in culture (Yan and Rivkees, 2006) and in vivo (Koeda et al., 1990). This may partly reflect damage to oligodendrocyte lineage cells, which are highly vulnerable to energy deprivation (Pantoni et al., 1996). The lack of energy causes a reversal of glutamate transporters that increases the extracellular glutamate concentration and thus activates AMPA/kainate receptors and NMDA receptors, which trigger damage to oligodendrocytes (Li et al., 1999; Káradóttir et al., 2005; Salter and Fern, 2005; Micu et al., 2006; Fu et al., 2009) and OPCs (Fern and Möller, 2000; Follett et al., 2000; Káradóttir et al., 2008; Manning et al., 2008). Lack of energy may also inhibit myelination by limiting the 
availability of substrates for the synthesis of the lipids in myelin. However, relatively little is known about the metabolism of oligodendrocytes and their preferred energy substrates.

Here, we investigate how lactate and glucose can sustain oligodendrocyte development and myelination, and the mechanism by which oligodendrocytes take up lactate. Using $\mathrm{pH}$ imaging, we show that oligodendrocytes take up lactate through monocarboxylate transporters, identified by immunolabeling as MCT1. Using cultured slices of developing cerebral cortex, we show that lactate can support oligodendrocyte development and myelination when glucose levels are low.

\section{Materials and Methods}

Animals. For pH imaging and patch-clamp experiments, Sprague Dawley rats at postnatal day 12 (P12) were used. Adult (300 g) male Wistar rats were used for postembedding immunogold electron microscopy. For confocal light microscopic immunofluorescence experiments, Sprague Dawley and Wistar rats from P12 to adult (300 g) were used. For organotypic slice cultures, we used transgenic mice (at P8) in which expression of green fluorescent protein (GFP) was under control of the oligodendrocyte-specific transcription factor Sox 10, making all oligodendrocyte lineage cells fluoresce green (Kessaris et al., 2006).

Slice preparation. Animals were killed by cervical dislocation and then decapitated in accordance with United Kingdom legislation. For pH imaging experiments, $225 \mu \mathrm{m}$ sagittal slices from the vermis of the rat cerebellum or coronal slices from the rat cerebral cortex (containing the corpus callosum) were cut with a vibratome in the slicing solution described below. For organotypic slice cultures, $325 \mu \mathrm{m}$ coronal slices from the mouse cerebral cortex were cut in EBSS with 25 mM HEPES added, $\mathrm{pH}$ 7.3.

Solutions. Acute brain slices were cut in solution containing the following (in mM): $124 \mathrm{NaCl}, 26 \mathrm{NaHCO}_{3}, 1 \mathrm{NaH}_{2} \mathrm{PO}_{4}, 2.5 \mathrm{KCl}, 4 \mathrm{MgCl}_{2}$, $2.5 \mathrm{CaCl}_{2}, 10$ glucose, and 1 kynurenic acid, gassed with $95 \% \mathrm{O}_{2} / 5 \%$ $\mathrm{CO}_{2}, \mathrm{pH}$ 7.4. For $\mathrm{pH}$ imaging, a HEPES-buffered extracellular solution was used, containing the following (in $\mathrm{mM}$ ): $144 \mathrm{NaCl}, 10$ HEPES, 1 $\mathrm{NaH}_{2} \mathrm{PO}_{4}, 2.5 \mathrm{KCl}, 2 \mathrm{MgCl}_{2}, 2.5 \mathrm{CaCl}_{2}$, and 10 glucose, adjusted to $\mathrm{pH} 7.4$ with $\mathrm{NaOH}$, gassed with $100 \% \mathrm{O}_{2}$. When $10 \mathrm{~mm} \mathrm{Na-L-lactate}$ was added to the extracellular solution, $10 \mathrm{~mm} \mathrm{NaCl}$ was removed to compensate for the osmolarity change. Intracellular solution for single-cell imaging contained the following (in mM): $140 \mathrm{KCl}, 0.5 \mathrm{CaCl}_{2}, 5 \mathrm{Na}_{2}$ EGTA, 0.5 HEPES, $2 \mathrm{MgCl}_{2}, 4$ $\mathrm{Na}_{2} \mathrm{ATP}$, and $96 \mu \mathrm{M} 2^{\prime}, 7^{\prime}$-bis-(2-carboxyethyl)-5-(and-6)-carboxyfluorescein (BCECF) acid (a pH-sensitive fluorescent dye), adjusted to $\mathrm{pH} 7.3$ with $\mathrm{KOH}$.

Organotypic slices were cultured in medium containing 41.5 (the recommended level) (Stoppini et al., 1991; De Simoni and Yu, 2006), 10.5, $5.5,2.9$, or $1.4 \mathrm{~mm}$ glucose. All slices were cultured in medium with 41.5 mm glucose for the 3 first days. When used, low-glucose treatment started on the third day in vitro (DIV3). The medium was then replaced every $3 \mathrm{~d}$. For lactate experiments, $20 \mathrm{~mm} \mathrm{Na}$-D-lactate or Na-L-lactate (SigmaAldrich) was added to solutions containing 41.5 and $2.9 \mathrm{~mm}$ glucose (added on DIV3 and then every $3 \mathrm{~d}$ ). When D- or L-lactate was added, it was substituted for $20 \mathrm{~mm} \mathrm{NaCl}$.

All culture media contained $25 \%$ horse serum (Invitrogen; catalog \#26050070), penicillin (25 U/ml), streptomycin ( $25 \mu \mathrm{g} / \mathrm{ml}), 1.125 \%$ nystatin $(12.5 \mathrm{U} / \mathrm{ml}), 5 \mathrm{~mm}$ Tris base, and the following additional components. Culture medium with $41.5 \mathrm{~mm}$ glucose contained 50\% Minimal Essential Medium (MEM) (Invitrogen; catalog \#41090028), 23\% Earl's balanced salt solution (EBSS) (Invitrogen; catalog \#24010043), and 36 $\mathrm{mm}$ glucose was added to give a final concentration of $41.5 \mathrm{~mm}$ (horse serum, MEM, and EBSS contain $5.5 \mathrm{~mm}$ glucose). Culture medium with 10.5 or $5.5 \mathrm{~mm}$ glucose contained $50 \%$ MEM, $23 \%$ EBSS, and 5 or $0 \mathrm{~mm}$ glucose was added to give a final concentration of 10.5 or $5.5 \mathrm{~mm}$, respectively ( 15.5 or $18 \mathrm{~mm} \mathrm{NaCl}$ was added, respectively, to compensate for the osmolarity changing with less glucose in the solution). Culture medium with 2.9 mu glucose contained 50\% glucose free DMEM (Sigma-Aldrich; D5030; with $4 \mathrm{~mm}$ L-alanyl-glutamine added as a glutamine source), $23 \%$ EBSS, and $0.3 \mathrm{~mm}$ glucose was added to give a final concentration of 2.9 $\mathrm{mm}$ ( $18 \mathrm{~mm} \mathrm{NaCl}$ was added to compensate for the osmolarity change). Culture medium with $1.4 \mathrm{~mm}$ glucose contained $73 \%$ glucose-free
DMEM (18 mM NaCl was added to compensate for the osmolarity change). Because the EBSS, MEM, and DMEM contain 0, 5.3, and 10.9 mu total amino acids, respectively (and the amino acids from the serum are the same in all the media), it follows that the $1.4 \mathrm{~mm}$ glucose medium contains $2.5 \mathrm{~mm}$ more amino acids than the $2.9 \mathrm{~mm}$ glucose medium, and $5.3 \mathrm{~mm}$ more amino acids than the high-glucose medium. Some of the extra amino acids could in principle be used as substrates for ATP production, but in fact, as described below, the cells survived less well in 1.4 mm glucose medium than in the higher glucose media, indicating that the lowered glucose concentration had the dominant effect on survival. Experiments examining the effect of $\mathrm{L}$ - and D-lactate on myelination were done in $2.9 \mathrm{~mm}$ glucose medium with constant amino acid composition.

pH imaging. MCTs cotransport lactate and $\mathrm{H}^{+}$, so their activity can be monitored from the $\mathrm{pH}$ change they produce (Meredith et al., 2002). We used confocal imaging and the $\mathrm{pH}$-sensitive dye BCECF to study $\mathrm{pH}$ changes evoked by application of lactate. For simultaneous $\mathrm{pH}$ imaging of many cells in the white matter, slices were incubated for $30 \mathrm{~min}$ in slicing solution containing $10 \mu \mathrm{M}$ of the acetoxymethyl ester of BCECF (BCECF-AM) (Invitrogen) together with $0.01 \%$ pluronic acid (Invitrogen) at room temperature. Slices were then transferred to slicing medium for $45 \mathrm{~min}$ at room temperature to allow deesterification to occur. The whole procedure was performed in the dark. For $\mathrm{pH}$ imaging of single cells, white matter oligodendrocytes were whole-cell patch-clamped at $-60 \mathrm{mV}$ (series resistance was 15-50 M $\Omega$ ) and filled with intracellular solution containing $96 \mu \mathrm{M}$ BCECF acid (Invitrogen) through the patch pipette. Oligodendrocytes were identified by their characteristic morphology when filled with fluorescent dye. The imaging was performed on a LSM 5 Pascal confocal microscope (Zeiss). The slices were superfused with a HEPES-buffered extracellular solution and bubbled with $100 \% \mathrm{O}_{2}$. MCT inhibitors used were phloretin (100 $\mu \mathrm{M}$; Sigma-Aldrich), 5-nitro-2-(3phenylpropylamino)-benzoate (NPPB) (Research Biochemicals International; $100 \mu \mathrm{M}$ ), and $\alpha$-cyano-4-hydroxycinnamate (4-CIN) (Sigma-Aldrich; 1 $\mathrm{mM}$ ). Phloretin and NPPB were applied during the imaging, whereas $20 \mathrm{~min}$ preincubation was necessary to see an effect of 4 -CIN as reported previously (Wender et al., 2000). Thus, for experiments using 4-CIN, the imaging was discontinued (to avoid bleaching of the dye) for 20 min while incubating with the inhibitor. Controls for this experiment were given the same treatment (discontinued imaging for $20 \mathrm{~min}$ ), but with no 4-CIN.

The excitation wavelengths were $488 \mathrm{~nm}$, for which the emitted fluorescence decreases when the $\mathrm{pH}$ goes more acid, and $458 \mathrm{~nm}$ (closer to the isosbestic wavelength of $440 \mathrm{~nm}$ at which the fluorescence is independent of $\mathrm{pH}$ ), and emitted light $>505 \mathrm{~nm}$ was monitored. Pictures were taken every $40 \mathrm{~s}$ with a $40 \times$ water-immersion objective. Changes of $\mathrm{pH}$ were monitored using the ratio of [emitted light with $488 \mathrm{~nm}$ excitation]/[emitted light with $458 \mathrm{~nm}$ excitation]. The emission gain for both wavelengths was adjusted for each slice so that the fluorescence was recorded at as high a gain as possible without saturating the detector; as a result, the apparent fluorescence ratio at the start of the experiment varied between slices. When using NPPB, the emitted light at 488 excitation was monitored, not the $488 / 458$ ratio, because NPPB absorbs 458 $\mathrm{nm}$ light (our unpublished observations).

Organotypic slice cultures. Using Sox10-GFP mice allowed us to develop an assay for myelination in brain slices in which oligodendrocyte lineage cells fluoresce green, and neuronal axons and myelin are identified and quantified with immunofluorescence. This method, which will be described in detail elsewhere (N. B. Hamilton and D. Attwell, unpublished observations), has the advantage that one can assess whether changes in the amount of myelination occurring reflect changes in the number of oligodendrocyte lineage cells, changes in the number of axons, or changes of the myelinating activity per oligodendrocyte lineage cell. Slices from 8-d-old transgenic mice were cut and cultured (De Simoni and $\mathrm{Yu}, 2006)$ on polytetrafluoroethylene filter membranes $(0.45$ $\mu \mathrm{m}$ pore size; Millipore) lying on $30 \mathrm{~mm}$ culture plate inserts $(0.4 \mu \mathrm{m}$ pore size; Millicell; Millipore) in culture dishes with wells containing $1 \mathrm{ml}$ of culture medium. The cultures were kept at $37^{\circ} \mathrm{C}$ in a humidified atmosphere with $5 \% \mathrm{CO}_{2}$. After 2 weeks, the slices (together with the filter membranes) were fixed and immunolabeled with markers for myelin [myelin basic protein (MBP), red-emitting secondary antibody with peak emission wavelength $555 \mathrm{~nm}$ ] and axons [neurofilament 200 
(NF200), far red-emitting secondary antibody with peak emission wavelength at $665 \mathrm{~nm}$ : this emission is recolored blue in the pictures below]. Pictures were taken on a LSM 510 Meta confocal microscope (Zeiss) using a $10 \times \mathrm{ob}$ jective. Since large white matter tracts like the corpus callosum often seemed to die during the 2 weeks in culture (our unpublished observations), images were taken of myelination within the gray matter of the cortex, covering layers I-VI. For each cultured slice, two confocal $z$-stacks covering the thickness of the slice were taken. The myelination was quantified by measuring the intensity of MBP labeling relative to the axon labeling (NF200), averaging the fluorescence intensity in the three stack images with the strongest labeling.

Immunofluorescence labeling. Slices were fixed in $4 \%$ paraformaldehyde for $1 \mathrm{~h}$, and then rinsed in $0.01 \mathrm{M}$ PBS followed by preincubation in $0.05 \%$ Triton and $10 \%$ goat serum in $0.01 \mathrm{M}$ PBS for at least $4 \mathrm{~h}$ at room temperature. The slices were then incubated with primary antibodies overnight at room temperature, rinsed in PBS, incubated with secondary antibodies for $4 \mathrm{~h}$, and rinsed again in PBS. Primary antibodies for myelin assessment in cultured slices were rat anti-myelin basic protein (amino acids 82-87; 1:200; Millipore) and chicken antineurofilament, NF200 IgY (1:10,000; Abcam). Secondary antibodies for myelin assessment were Alexa 555 goat anti-rat (1:200; Invitrogen) and Cy5 goat anti-chicken (1:200; Jackson ImmunoResearch). Primary antibodies for acute rat brain slices were rat anti-myelin basic protein (amino acids 82-87; 1:200; Millipore), chicken anti-monocarboxylate transporter 1 (C terminus; IgY; 1:400; Millipore), rabbit antimonocarboxylate transporter 2 ( $\mathrm{C}$ terminus; 1:100), and rabbit anti-monocarboxylate transporter 4 (C terminus; 1:100). The antibodies against monocarboxylate transporters 2 and 4 (Poole et al., 1996; Jackson et al., 1997; Wilson et al., 1998) were kindly provided by Dr. Maz Wilson and Prof. Andrew Halestrap (Department of Biochemistry, School of Medical Sciences, University of Bristol, Bristol, UK). Secondary antibodies for acute rat brain slices were Alexa 633 goat anti-rat (1:500; Invitrogen; emitted light $>650 \mathrm{~nm}$ was captured; this emission is recolored red in images below), Alexa 555 goat anti-rabbit (1:500; Invitrogen; emitted light between 560 and $615 \mathrm{~nm}$ was captured; recolored green in images below), and Alexa 488 goat anti-chicken (1:1000; Invitrogen; emitted light between 505 and $530 \mathrm{~nm}$ was captured). Pictures were taken on a LSM 5 Pascal confocal microscope (Zeiss) with a 40 or $63 \times$ objective.

Tissue preparation and staining procedure for postembedding immunogold labeling. Small rectangular pieces from the vermis of rat cerebellum $(\sim 0.5 \times$ $0.5 \times 1 \mathrm{~mm}$ ) were cryoprotected by immersion in graded concentrations of glycerol $(10,20$, and $30 \%)$ in $0.1 \mathrm{M}$ phosphate buffer $\left(75 \mathrm{~mm} \mathrm{Na}_{2} \mathrm{HPO}_{4}\right.$ and $25 \mathrm{~mm} \mathrm{NaH}_{2} \mathrm{PO}_{4}, \mathrm{pH}$ 7.4). The samples were then plunged into liquid propane cooled to $-170^{\circ} \mathrm{C}$ by liquid nitrogen in a Universal Cryofixation System KF80 (Reichert-Jung). For freeze-substitution (Chaudhry et al., 1995; Bergersen et al., 2008), the samples were immersed in a solution of anhydrous methanol and $0.5 \%$ uranyl acetate overnight at $-90^{\circ} \mathrm{C}$. The temperature was then raised stepwise in $4^{\circ} \mathrm{C}$ increments per hour from -90 to $-45^{\circ} \mathrm{C}$, where it was kept for the subsequent steps. The tissue samples were washed several times with anhydrous methanol to remove residual water and uranyl acetate, and then infiltrated in the embedding resin Lowicryl HM20 stepwise from Lowicryl/methanol 1:2, 1:1, and 2:1 (1 h each) to pure Lowicryl (overnight). Polymerization was catalyzed by $360 \mathrm{~nm}$ ultraviolet light for $2 \mathrm{~d}$ at $-45^{\circ} \mathrm{C}$ followed by $1 \mathrm{~d}$ at room temperature. Ultrathin secto lactate in region $\mathrm{R} 3\left(F_{488} / F_{458}\right)$.
B

Fluorescence intensity in R1 excited at 488 and $458 \mathrm{~nm}$

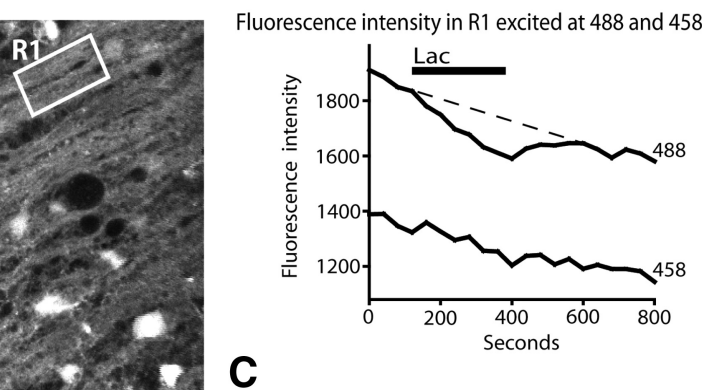

C

Ratio of fluorescence $(488 \mathrm{~nm} / 458 \mathrm{~nm})$ in R1

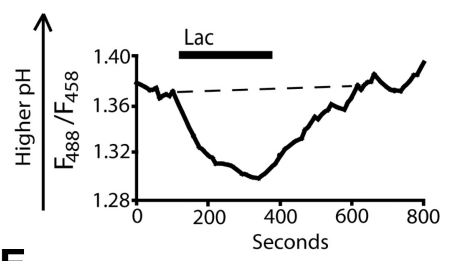

E

Ratio of fluorescence $(488 \mathrm{~nm} / 458 \mathrm{~nm})$ in R3

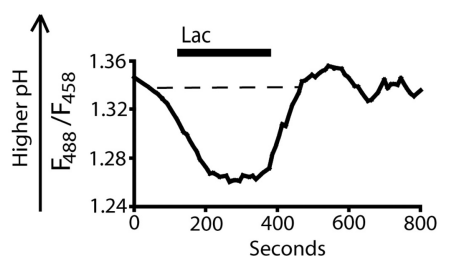

Figure 1. Lactate uptake in corpus callosum generates an intracellular pH change. Cell bodies and processes aligned with axons, which are presumed to be oligodendrocyte processes, in corpus callosum loaded with BCECF-AM, respond to lactate with a 3 is a cell body (this soma was chosen to have a fluorescence level that does not saturate the detector). $\boldsymbol{B}$. The fluorescence response to $10 \mathrm{~mm}$ lactate in region $\mathrm{R} 1$ at excitation wavelengths 488 and $458 \mathrm{~nm}$. $C$, The fluorescence response $(F)$ to lactate in region $\mathrm{R} 1$ shown as the ratio $F_{488} / F_{458}$. D , The fluorescence response to lactate in region $\mathrm{R} 2\left(F_{488} / F_{458}\right)$. $\boldsymbol{E}$, The fluorescence response

tions (90 nm) were cut by a diamond knife on a Reichert-Jung ultramicrotome and mounted on nickel grids with an adhesive pen (David Sangyo).

The grids with the ultrathin sections were first washed in Tris-buffered saline (50 mu Tris- $\mathrm{HCl}$ buffer, $\mathrm{pH} 7.4$, and $150 \mathrm{~mm} \mathrm{NaCl}$ ) containing $\mathrm{H}_{2} \mathrm{O}_{2}$ followed by Tris-buffered saline with $0.1 \%$ Triton X-100 (TBST) containing $2 \%$ human serum albumin (HSA). They were then incubated overnight with primary antibodies diluted in TBST containing $2 \%$ HSA, followed by $2 \mathrm{~h}$ incubation with secondary antibodies diluted in TBST containing 2\% HSA. The secondary antibody solution was spun at $1000 \mathrm{rpm}$ for $1 \mathrm{~min}$ before use to sediment aggregated gold particles. Primary antibodies for electron microscopy were chicken antimonocarboxylate transporter 1 (C terminus; IgY; 1:500; Millipore) and rabbit anti-monocarboxylate transporter 2 (C terminus; 1:100; Prof. Andrew Halestrap) (see above). Secondary antibodies for electron microscopy were goat anti-chicken coupled to $15 \mathrm{~nm}$ gold particles (1:20; Aurion Immunoresearch) and goat anti-rabbit coupled to $10 \mathrm{~nm}$ gold particles (1:20; British Biocell International). The ultrathin sections were contrasted in uranyl acetate $(5 \%)$ and lead citrate $(30 \%)$, before they were observed in a Philips CM100 electron microscope. Pictures were taken from the white matter at a primary magnification of 34,000 . The density of gold particles was quantified in myelin, axons, endothelial cells (MCT1), and postsynaptic densities (parallel fiber-Purkinje cell synapses in the molecular layer; MCT2) using an overlay screen (Landsend et al., 1997; Bergersen et al., 2008). Gold particles situated within $30 \mathrm{~nm}$ of the membrane/compartment were included [i.e., approximately the same distance as the lateral resolution of the immunogold method (Chaudhry et al., 1995; Bergersen et al., 2008)]. 

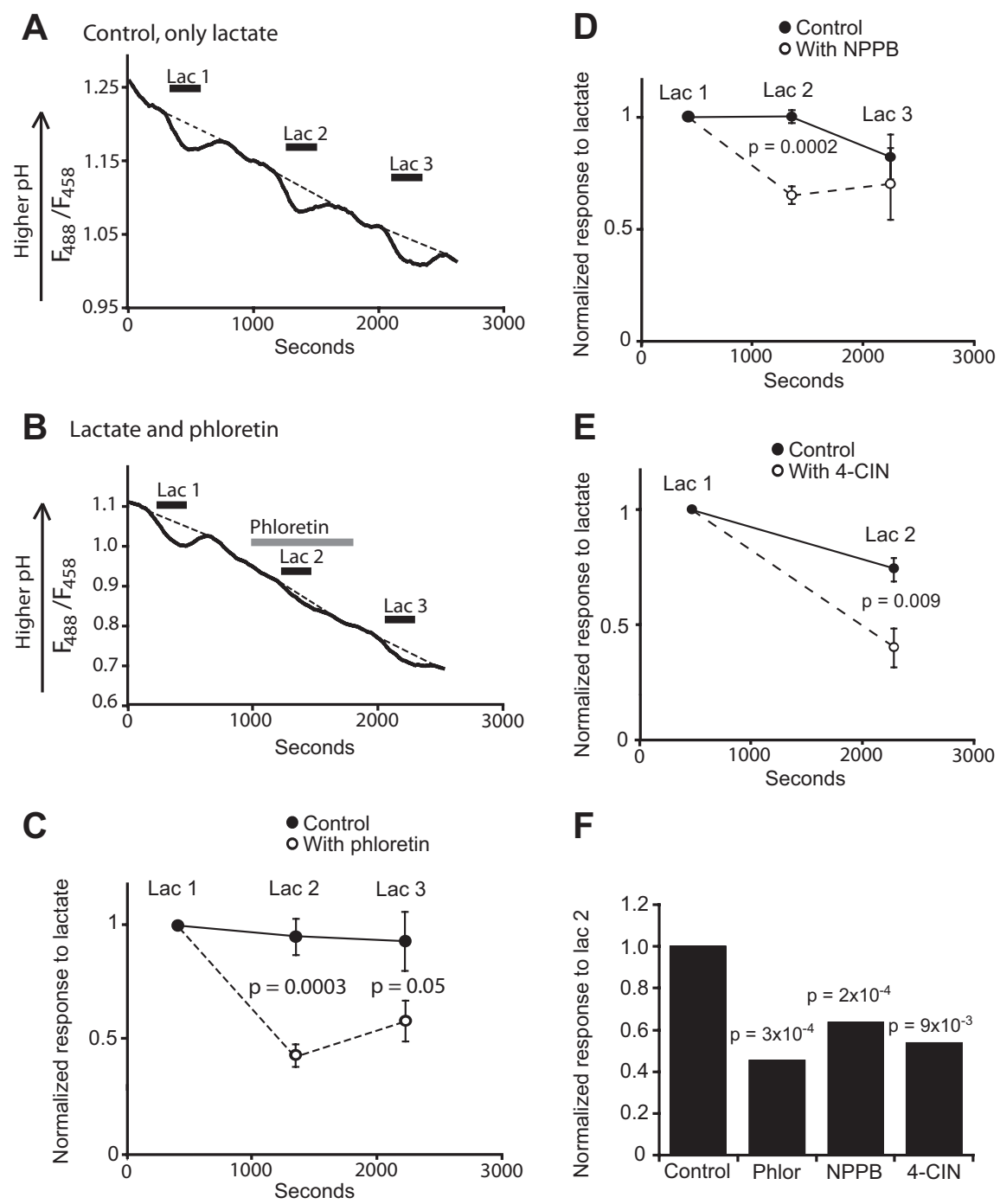

Figure 2. The MCT inhibitors phloretin, 4-CIN, and NPPB reduced the $\mathrm{pH}$ response to lactate in the corpus callosum. $\boldsymbol{A}$, Three successive pH responses (measured from regions encompassing numerous BCECF-loaded processes and somata in the corpus callosum) to $10 \mathrm{~mm}$ lactate. $\boldsymbol{B}$, As in $\boldsymbol{A}$, but with $100 \mu \mathrm{m}$ phloretin present during the second response. $\boldsymbol{C}$, The mean responses to lactate \pm SEM with and without phloretin in six slices for each condition. $\boldsymbol{D}$, The mean responses to lactate with and without 100 $\mu \mathrm{M} \mathrm{NPPB} \mathrm{(} n=4$ and 6 slices, respectively). $\boldsymbol{E}$, The mean responses to lactate with and without $1 \mathrm{~mm} 4$ - CIN ( $n=5$ and 6 slices,

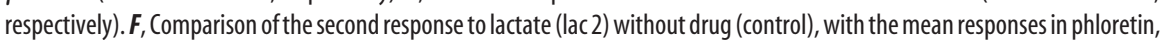
4-CIN, or NPPB. All the inhibitors reduced the lactate response. Values of $p$ are from two-tailed $t$ tests comparing the second responses in control and drug conditions as in $\mathbf{C}-\boldsymbol{E}$.

Statistics. Data are presented as mean \pm SEM. Values of $p$ are from Student's $t$ tests (for single comparisons) or one-way ANOVA with Dunnett's post hoc test for multiple comparisons. When averaging fluorescence data over different brain slices to quantify myelination, within each experiment data were normalized to the average fluorescence value obtained for $41.5 \mathrm{~mm}$ glucose, and data were then averaged over the repeated experiments performed. ANOVA showed that most variability in the data was between different slices rather than between experiments, and so we used the number of slices as the number of observations for statistical calculations.

\section{Results}

Lactate uptake in the white matter

We performed time-lapse confocal microscopy of acute brain slices loaded with the acetoxymethyl ester of the $\mathrm{pH}$-sensitive dye BCECF (BCECF-AM). A decrease in fluorescence intensity excited at 488 $\mathrm{nm}$, but no change in fluorescence excited at $458 \mathrm{~nm}$ indicates acid- ification of the tissue. In the corpus callosum, cell bodies and processes aligned with axons (presumed to be oligodendrocyte processes) showed a decrease in $\mathrm{pH}$ when 10 mm lactate was applied (Fig. $1 A, B$ ), indicating that lactate is transported into the cells via MCTs that cotransport $\mathrm{H}^{+}$with each lactate molecule. The mean decrease in fluorescence when excited at $488 \mathrm{~nm}$ was $5.58 \pm 0.76 \%$ ( $n=6$ slices $)$.

The acidification produced by lactate was superimposed on slowly declining baseline signals evoked at 488 and $458 \mathrm{~nm}$ (Fig. $1 B)$, which can lead to an apparent acidification of the cell when assessed as the ratio of signals evoked at 488 and $458 \mathrm{~nm}$ (Fig. $2 A)$ and probably reflect slow bleaching of the dye as reported by Weiner and Hamm (1989). This baseline decline, which was subtracted for quantitative analysis of the signals, was not observed in BCECF signals evoked from cells loaded with dye from the patch pipette (see below), for which fresh (unbleached) dye can diffuse in from the pipette. Applying lactate to an unloaded slice (no BCECF-AM) gave a negligible $0.4 \%$ decrease in fluorescence, and this background change in fluorescence was not subtracted from the data. In BCECF-loaded slices, the mean change in the ratio (fluorescence excited at $488 \mathrm{~nm}$ )/(fluorescence excited at $458 \mathrm{~nm}$ ) in response to lactate (Fig. $1 C-E$ ) was $0.050 \pm 0.006$.

The activity of MCTs is reduced by the blockers phloretin (Garcia et al., 1995; Bröer et al., 1999), NPPB (Carpenter and Halestrap, 1994), and 4-CIN (Poole and Halestrap, 1993; Bröer et al., 1998). For MCTs 1, 2, and 4, the uptake of $10 \mathrm{~mm}$ lactate is predicted to be blocked by $34-$ $65 \%$ using $100 \mu \mathrm{M}$ phloretin, by $24-74 \%$ using $100 \mu \mathrm{M}$ NPPB, and by $38-75 \%$ using $1 \mathrm{~mm}$ 4-CIN [assuming competitive inhibition, and using $\mathrm{IC}_{50}$ and $K_{\mathrm{i}}$ values from Bröer et al. (1999) for phloretin and 4-CIN in MCT1 and 2, Carpenter and Halestrap (1994) for NPPB in MCT1, and Manning Fox et al. (2000) for phloretin, $\mathrm{NPPB}$, and 4-CIN in MCT4]. All these blockers reduced the $\mathrm{pH}$ response to lactate (Fig. 2). Three successive applications of lactate (separated by $10 \mathrm{~min}$ ) gave $\mathrm{pH}$ responses of a similar size (Fig. 2A). With $100 \mu \mathrm{M}$ phloretin present during the second application of lactate, the response was reduced by $54 \%$ ( $p=$ 0.0003 ) (Fig. $2 B, C, F$ ), whereas $100 \mu \mathrm{M}$ NPPB reduced the lactate response by $35 \%(p=0.0002)$ (Fig. $2 D, F)$, and $1 \mathrm{~mm} 4$-CIN reduced the response by 55\% ( $p=0.009$ ) (Fig. $2 E, F)$. After the long preincubation needed for 4-CIN to inhibit lactate uptake, the BCECF fluorescence was too weak to reliably quantify the response to lactate after 4 -CIN was removed.

To test whether the response to lactate was restricted to the corpus callosum, we performed similar $\mathrm{pH}$ imaging in the cerebellar white matter. As in the corpus callosum, application of $10 \mathrm{~mm}$ lactate lowered the $\mathrm{pH}$ in cell bodies and processes 
aligned with axons (Fig. $3 A, B$ ). The mean change in $488 / 458 \mathrm{~nm}$ fluorescence ratio was $0.077 \pm 0.015(n=5$ slices). This response was inhibited by the MCT inhibitor phloretin $(p=$ 0.005 ) (Fig. $3 C, D$ ). The $\mathrm{pH}$ response to lactate in the white matter was similar to that in the adjacent granule cell layers (95 $\pm 7 \%$ of the value in the adjacent gray matter in five slices).

To test whether the response seen in the white matter in processes anatomically resembling oligodendrocytes was indeed attributable to lactate uptake into oligodendrocytes and not into axons or astrocytes, oligodendrocytes from the corpus callosum and cerebellar white matter were whole-cell patch clamped and filled with BCECF through the patch pipette. Application of $10 \mathrm{~mm}$ lactate evoked a $\mathrm{pH}$ response in the oligodendrocytes similar to that seen in the white matter of slices loaded with BCECF-AM. A $\mathrm{pH}$ response was seen both in the processes of the cells and in their somata (Fig. $3 E)$. The average response ratio $(488 / 458$ $\mathrm{nm}$ ) to lactate was $0.86 \pm 0.36$ in the processes of the cells ( $n=6$ cells) and $0.25 \pm$ 0.08 in their somata ( $n=12$ cells) after the background autofluorescence was subtracted (for each time-lapse series, the background at a location distant from the cell was measured and subtracted from the fluorescence of the cell). The mean background autofluorescence (away from the filled cell) at $488 \mathrm{~nm}$ excitation was 4 and $14 \%$ of the fluorescence measured from the soma and processes, respectively, of the BCECF-loaded cell (before lactate was applied). Lactate produced no significant change $(p=0.6)$ in the response ratio $(488 / 458 \mathrm{~nm})$ at locations away from the patched cell $(-0.008 \pm$ 0.015 in 13 slices, where minus denotes in the opposite direction to the change seen in the dye-loaded cell).

\section{MCT1 is expressed in the myelin}

MCT1, MCT2, and MCT4 are expressed throughout the brain (Bergersen et al., 2007), whereas MCT3 is only present in retinal pigment and choroid plexus epithelia (Philp et al., 2001). To identify the MCT isoform(s) mediating lactate uptake into oligodendrocytes, we performed immunofluorescence labeling with antibodies against MCT1, MCT2, and MCT4 on fixed brain sections. MCT1 stained the myelin, colocalizing with MBP (Fig. 4A, white arrowheads). This staining was weaker than that seen in the blood vessel walls (Fig. 4A). MCT2 also appeared to colocalize with MBP (Fig. $4 B$, white arrowheads), but we suggest below that this is caused by the limited spatial resolution of light microscopy. MCT4 labeled astrocyte-like processes as previously reported (Rafiki et al., 2003) but did not colocalize with MBP (Fig. 4C). The fluorescence images in Figure 4 are from a 12-d-old rat, but similar labeling was seen in adult rats.

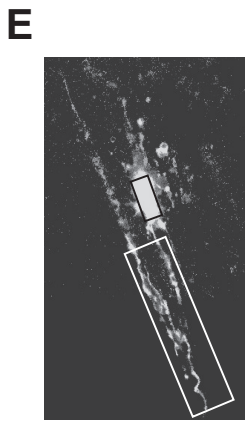

B Control, only lactate
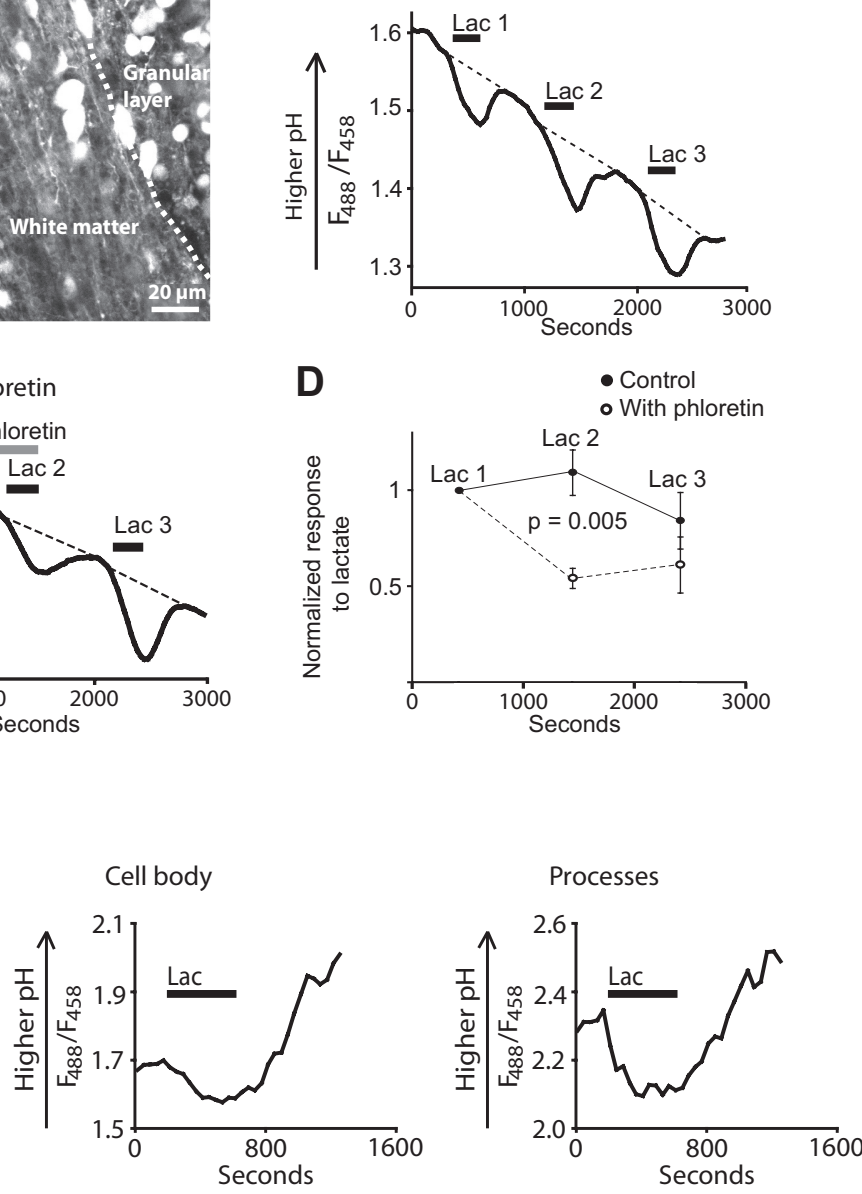

Figure 3. Lactate uptake in cerebellar white matter and in whole-cell patch-clamped oligodendrocytes. $\boldsymbol{A}$, Confocal image from the cerebellum showing white matter with granule cells on each side. $\boldsymbol{B}$, Three successive $\mathrm{pH}$ responses to $10 \mathrm{~mm}$ lactate measured in the white matter. $\boldsymbol{C}$, As in $\boldsymbol{B}$, but with $100 \mu \mathrm{m}$ phloretin present during the second response. $\boldsymbol{D}$, The mean responses to lactate igodendrocyte in the cerebellar white matter filled with BCECF from the pipette. Left, Fluorescence image of the oligodendrocyte. fluorescence response to $10 \mathrm{~mm}$ lactate in the soma of the cell. Right, The fluorescence response to lactate in the indicated processes. In both areas, lactate evokes a clear acidification, superimposed on some baseline drift.

The limited resolution of light microscopy makes it hard to distinguish between labeling of the axon and of myelin in myelinated axons. To overcome this problem, cerebellar white matter sections immunolabeled for MCT1 or MCT2 using the postembedding immunogold technique were observed in the electron microscope. Antibodies against MCT1 labeled the myelin and the endothelial cells of blood vessels (Fig. 4D, left and right, respectively). There was also staining of mitochondrial membranes (Fig. $4 D$, left), as previously reported (Butz et al., 2004; Hashimoto et al., 2008). The density of gold particles representing MCT1 was significantly higher in myelin and endothelial cells compared with axons $\left(p=7 \times 10^{-6}\right.$ and $3 \times 10^{-7}$, respectively) (Fig. $4 E$ ), implying that the colocalization of MCT1 with MBP seen with immunofluorescence is caused by MCT1 labeling the myelin. Unlike the immunofluorescence staining, the immunogold labeling showed no significant difference between endothelial cells and myelin (Fig. 4E).

Antibodies against MCT2 labeled axons (presumably indicating MCT2 in transport vesicles moving along the axon), with few gold particles in the myelin (Fig. $4 F$, left), suggesting 

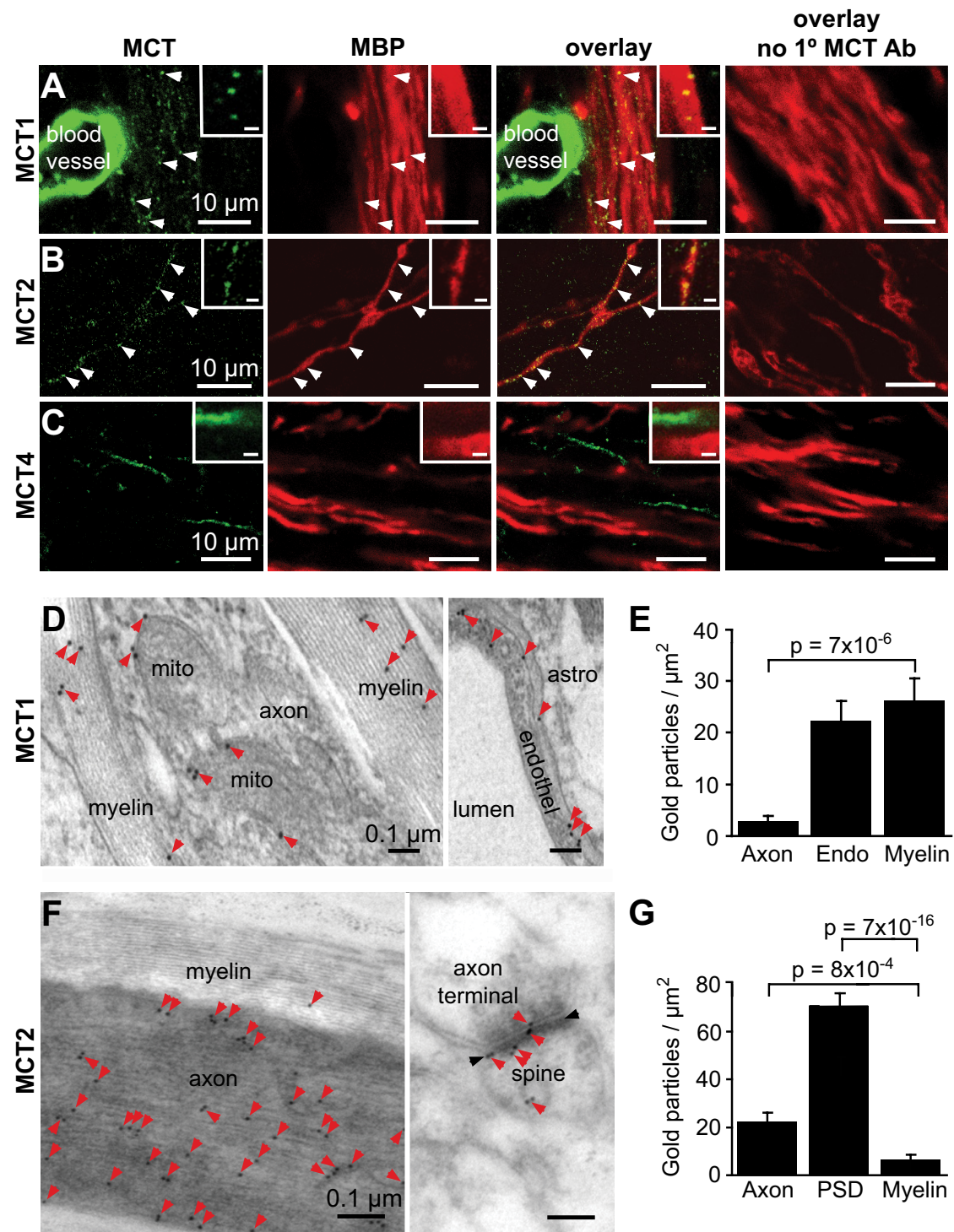

G

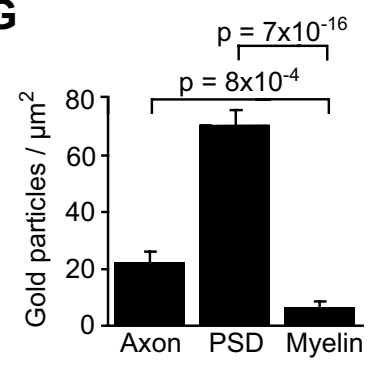

Figure 4. $\mathrm{MCT} 1$ is expressed in myelin. $\boldsymbol{A}-\boldsymbol{C}$, Single confocal images from the cerebellar white matter labeled with antibodies to MBP, MCT1 $(\boldsymbol{A})$, MCT2 $(\boldsymbol{B})$, and MCT4 $(\boldsymbol{C})$. The insets are higher magnification images from each slice. Scale bars: insets, $1 \mu \mathrm{m} . \boldsymbol{A}$, MCT1 (green) strongly labels blood vessels, but some labeling is also seen in the myelin (MBP, red). Colocalization is seen as yellow spots in the overlay and is indicated by white arrowheads. $\boldsymbol{B}, \mathrm{MCT} 2$ (green) apparently colocalizes with MBP (red). Colocalization is seen as yellow spots in the overlay and is indicated by white arrowheads. However, EM studies (see $\boldsymbol{F}$ and main text) show that the MCT2 is actually in axons. C, MCT4 (green) labels processes presumed to be astrocytic but does not colocalize with MBP (red). D, Electron micrographs of a myelinated axon (left) and part of an endothelial cell surrounding a blood vessel lumen (right) in the cerebellar white matter labeled with antibodies to MCT1 coupled to gold particles ( $15 \mathrm{~nm}$ black dots indicated by red arrowheads) Mito, Mitochondrion; astro, astrocyte; endothel, endothelial cell. $\boldsymbol{E}$, Density of gold particles labeling MCT1 in white matter axons, endothelial cells (Endo), and myelin. $\boldsymbol{F}$, Electron micrographs of a myelinated axon in the cerebellar white matter (left) and a parallel fiber-Purkinje cell synapse in the cerebellar molecular layer (right) labeled with antibodies to MCT2 coupled to gold particles ( $10 \mathrm{~nm}$ black dots indicated by red arrowheads). G, Density of gold particles labeling MCT2 in axons, postsynaptic density (PSD) from parallel fiber-Purkinje cell synapses, and myelin. Error bars indicate SEM.

that the colocalization of MCT2 with MBP seen with immunofluorescence is attributable to MCT2 labeling the axons and not the myelin. Strong MCT2 labeling was seen in the postsynaptic density of parallel fiber-Purkinje cell synapses (Fig. $4 F$, right), as previously reported (Bergersen et al., 2001). There was a significantly higher density of particles representing MCT2 in axons compared with myelin $\left(p=8 \times 10^{-4}\right)$, whereas postsynaptic densities had a higher labeling than axons and myelin $\left(p=5 \times 10^{-10}\right.$ and $7 \times 10^{-16}$, respectively $)$ (Fig. 4G).
Effect of glucose concentration on oligodendrocyte development and myelination

To assess the possible function of the lactate transporters in oligodendrocytes, we studied the dependence of oligodendrocyte development and myelination on energy supply in cultured cortical slices. Slices from Sox10-GFP mouse brains (i.e., expressing GFP in oligodendrocyte lineage cells) were cultured for $14 \mathrm{~d}$ in medium containing 41.5 $\mathrm{mm}$ glucose, and then were immunolabeled for MBP (Fig. 5A, shown in red) and NF (Fig. 5A, blue). At $41.5 \mathrm{~mm}$ glucose, we observed normal myelination of axons in the cortex (Figs. 5A, left; $6 F$, left).

We then cultured slices in $41.5,10.5$, $5.5,2.9$, or $1.4 \mathrm{~mm}$ glucose to check whether the different glucose conditions affected myelination, the generation and survival of axons, or the number of Sox 10GFP cells. As the glucose concentration was reduced, MBP expression decreased, suggesting that less myelin was being formed (Fig. $5 A, B$; the graphs show pooled data from four separate experiments, using 22, 10, 23, 24, and 9 slices for $41.5,10.5,5.5,2.9$, and $1.4 \mathrm{~mm}$ glucose, respectively). In contrast, between 41.5 and $2.9 \mathrm{~mm}$ glucose, the neurofilament expression level was unchanged, implying no change in the number of axons present, and only when the glucose was reduced to $1.4 \mathrm{~mm}$ did neurofilament expression decrease (Fig. 5A,C). Similar to the expression of MBP, Sox10-GFP fluorescence was reduced at lower glucose concentrations, suggesting a reduction in the number of oligodendrocyte lineage cells (Fig. $5 A, D$ ). To check that GFP fluorescence could be used to monitor Sox10-GFP cell number even at low [glucose], the two variables were plotted against each other. GFP fluorescence was proportional to the number of Sox10-GFP cells present, even at low glucose concentrations (Fig. 5G), confirming that GFP intensity does not decrease at low glucose levels and that the (more quickly measured) GFP fluorescence accurately reflects Sox10-GFP cell number.

To obtain a measure for the amount of myelination per axon, we took the ratio of MBP fluorescence to that of neurofilament (MBP/NF) (Fig. 5E). MBP/NF was significantly reduced by lowering the glucose concentration. To see whether the reduction in myelin (MBP) level could be explained by a reduced number of oligodendrocyte lineage cells, we measured the ratio of the MBP fluorescence to that of Sox10-GFP (MBP/Sox10-GFP) (Fig. 5F), which gives an estimate of the myelin produced per oligodendrocyte lineage cell present (this procedure gave results similar to counting the number of GFP-expressing cells present and dividing the MBP fluorescence by this value). MBP/Sox10-GFP was 
A

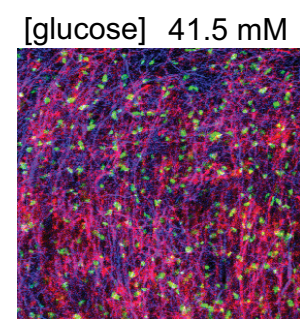

B Myelin Basic Protein (MBP)

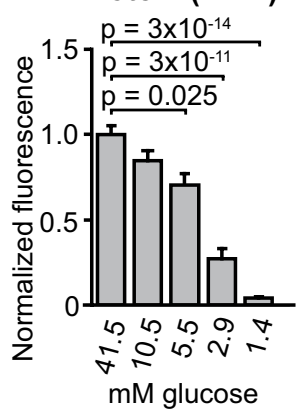

C Neurofilament (NF)

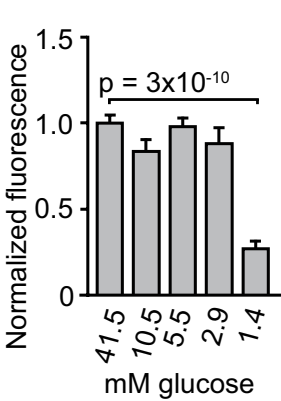
$10.5 \mathrm{mM}$

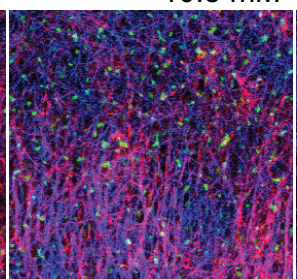

Myelin Basic Protein Neurofilament SOX10-GFP

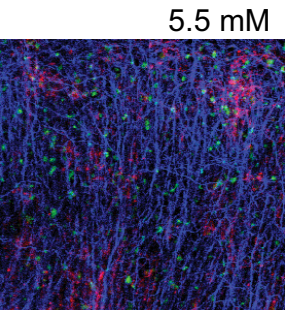

D Sox10-GFP

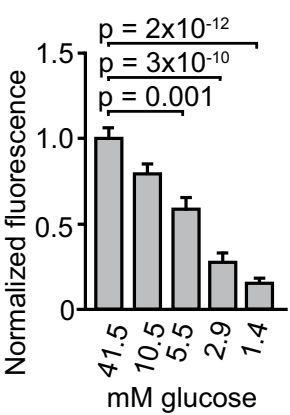

$2.9 \mathrm{mM}$

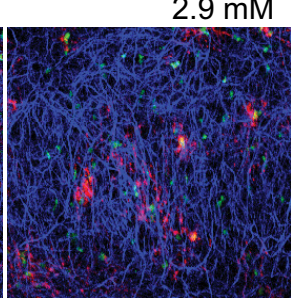

E MBP/NF ratio

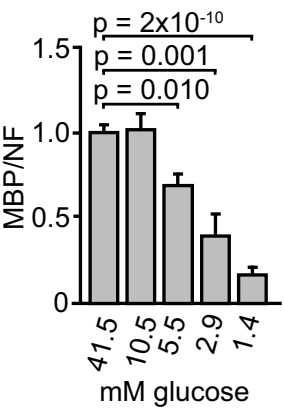

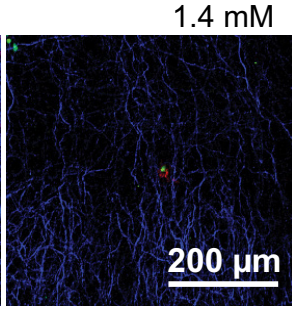

F MBP/Sox10GFP ratio

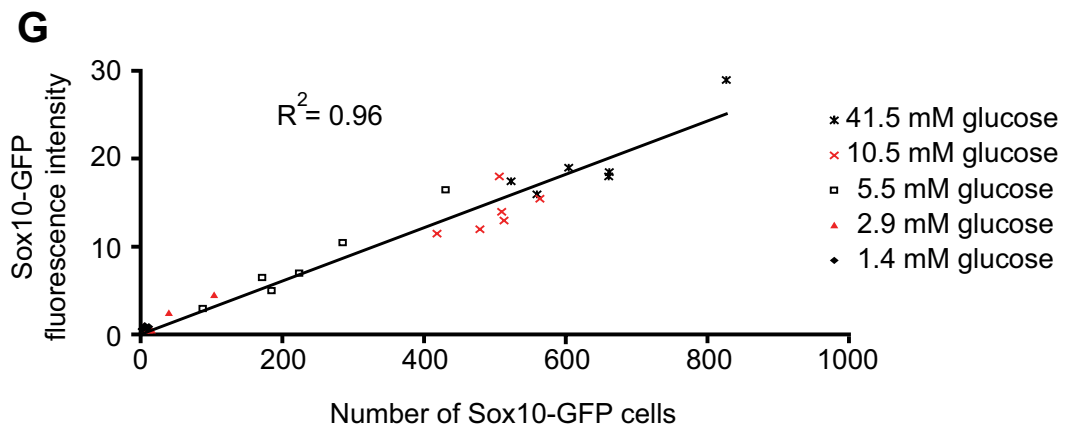

Figure 5. A decrease in glucose concentration inhibits oligodendrocyte development and myelination in cultured cortical brain slices. $A$, Images of the cerebral cortex in cultured brain slices from mice in which oligodendrocyte lineage cells express GFP under control of the Sox10 promoter. The slices were cultured in solution containing (from left to right) 41.5, 10.5,5.5, 2.9, and 1.4 mm glucose and immunolabeled for MBP (red) and NF (blue). Sox10-GFP is green. $\boldsymbol{B}$ - $\boldsymbol{D}$, Normalized fluorescence intensity (see Materials and Methods) for MBP (B), NF (C), and Sox10-GFP (D), pooled from four separate experiments, using a total of 22, 10,23,24, and 9 slices for 41.5, 10.5, 5.5, 2.9, and $1.4 \mathrm{~mm}$ glucose, respectively. $\boldsymbol{E}, \boldsymbol{F}$, Labeling intensity ratio for MBP/NF $(\boldsymbol{E})$ and $M B P / S$ ox $10-\mathrm{GFP}(\boldsymbol{F})$ in 41.5, 10.5, 5.5, 2.9, and 1.4 mm glucose. G, Sox10-GFP fluorescence (arbitrary units) versus number of Sox10-GFP cells (counted using ImageJ), demonstrating a linear relationship between the two in 30 slices cultured in $1.4-41.5 \mathrm{~mm}$ glucose (each point is one slice). Error bars indicate SEM.

not significantly changed between 41.5 and $2.9 \mathrm{~mm}$ glucose, implying that the reduction in myelin was attributable to the reduced number of oligodendrocyte lineage cells at these glucose concentrations (Fig. 5D). However, at $1.4 \mathrm{~mm}$ glucose, the MBP/Sox10-GFP ratio was reduced compared with $41.5 \mathrm{~mm}$ glucose, suggesting that, at this very low glucose level, in addition to the number of oligodendrocyte lineage cells being reduced, there was also a decrease in the myelin made per oligodendrocyte lineage cell present.

\section{L-Lactate rescues myelination in low-glucose solution}

To test whether L-lactate had an effect on myelination, on the formation and survival of axons, or on the number of Sox10-GFP cells, slices were cultured in medium with $20 \mathrm{~mm}$ L-lactate added (Fig. 6). At $41.5 \mathrm{~mm}$ glucose, L-lactate had no effect on MBP, NF, or Sox10-GFP labeling (Fig. 6A-E; pooled data from two experiments using 15 slices for control and D-lactate, and 10 slices for L-lactate). Thus, when glucose is abundant, the presence of the extra energy source lactate does not alter myelination.

To investigate possible effects of lactate when the glucose supply was compromised, we studied myelination at $2.9 \mathrm{~mm}$ glu- cose-a level that inhibits myelination without decreasing the number of neuronal axons present (Fig. 5C). At $2.9 \mathrm{~mm}$ glucose, slices with L-lactate added showed more MBP fluorescence than control slices cultured in $2.9 \mathrm{~mm}$ glucose alone; indeed, the lactate brought the MBP level back to that seen in $41.5 \mathrm{~mm}$ glucose (Fig. $6 F$, $G$; pooled data from two separate experiments, using 11 slices for $41.5 \mathrm{~mm}$ glucose, and 13 slices for each condition in $2.9 \mathrm{~mm}$ glucose). Thus, L-lactate rescues myelination from the reduction caused by the low glucose level. When added to $2.9 \mathrm{~mm}$ glucose, L-lactate had no effect on neurofilament labeling (Fig. $6 F, H$ ), implying that lactate did not alter the number of axons present. However, the Sox 10-GFP fluorescence was increased in slices cultured with $2.9 \mathrm{~mm}$ glucose and L-lactate, compared with control slices with only $2.9 \mathrm{~mm}$ glucose (Fig. $6 F, I$ ), almost reaching the level seen in $41.5 \mathrm{~mm}$ glucose, implying that L-lactate prevented the lack of oligodendrocyte lineage cells caused by the low concentration of glucose. The MBP/NF ratio was also increased (Fig. $6 J$ ), suggesting that lactate increased the myelination per axon compared with slices in $2.9 \mathrm{~mm}$ glucose alone. The MBP/Sox10-GFP ratio was increased by 


\section{A Myelin Basic} Protein (MBP)

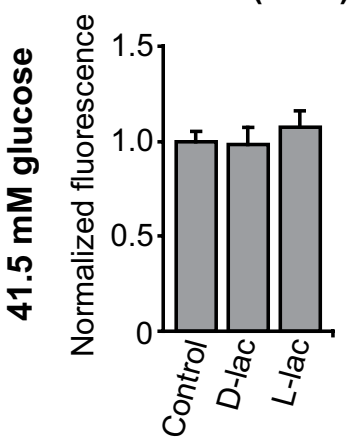

B Neurofilament (NF)

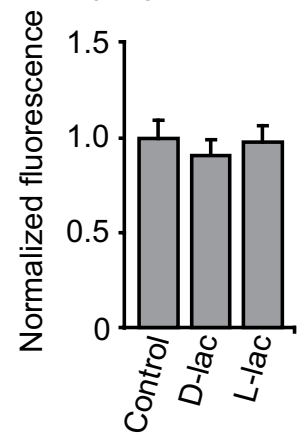

C Sox10-GFP

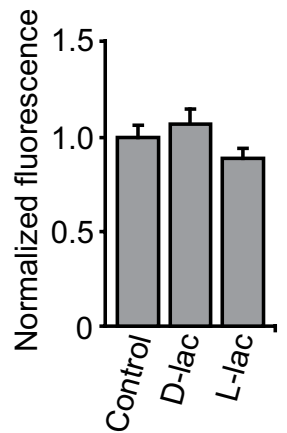

D MBP/NF ratio

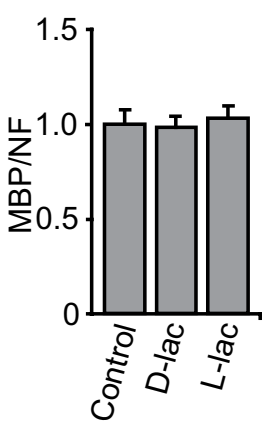

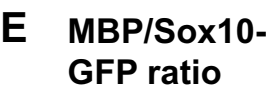

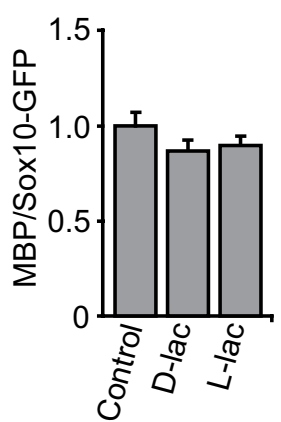

$\mathbf{F}$

Myelin Basic Protein Neurofilament SOX10-GFP
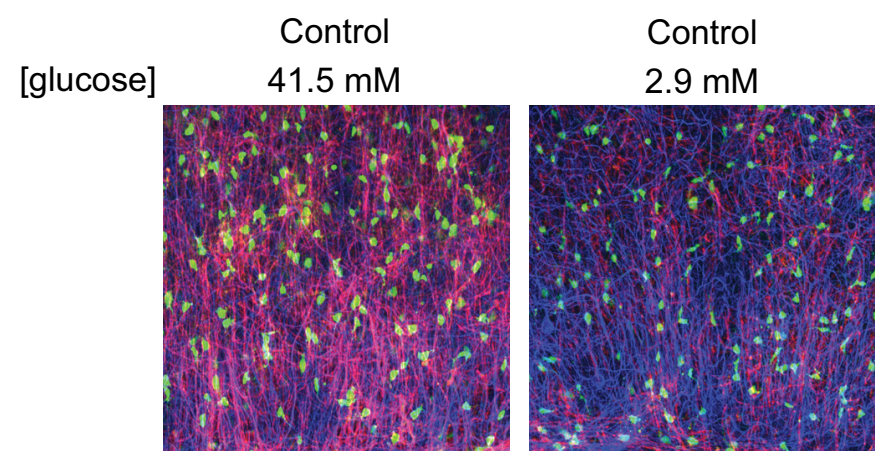

G $\begin{aligned} & \text { Myelin Basic } \\ & \text { Protein (MBP) }\end{aligned}$

H Neurofilament I Sox10-GFP (NF)

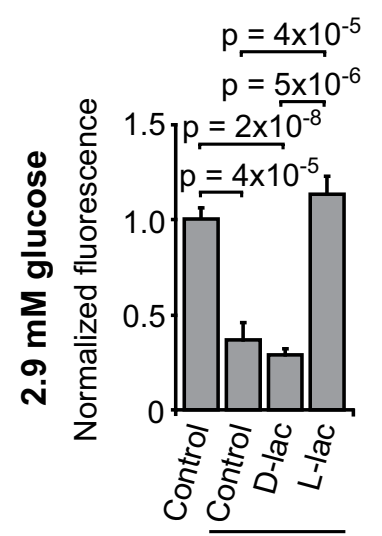

glucose $41.5 \quad 2.9$ (mM)
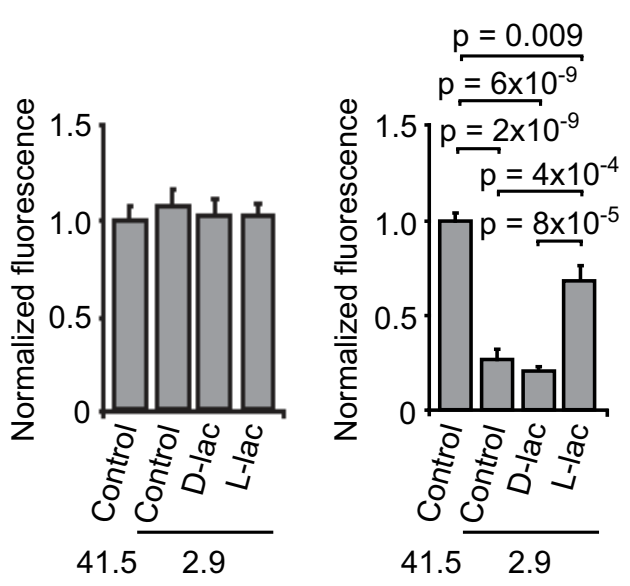

J MBP/NF ratio
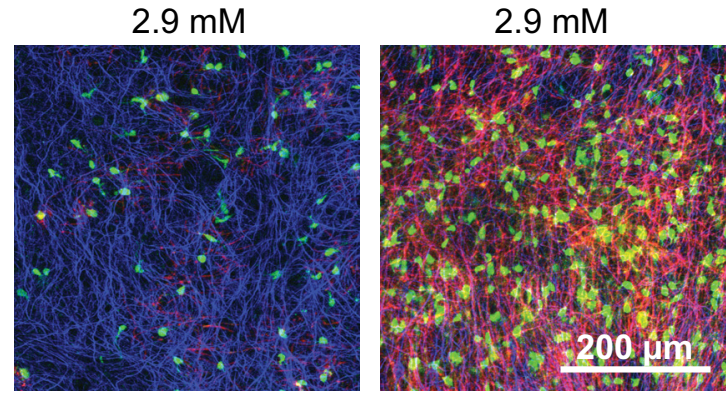

Figure 6. The effect of $L$-and D-lactate on oligodendrocyte development and myelination in 41.5 and 2.9 mm glucose. $\boldsymbol{A}$ - $\boldsymbol{C}$, Normalized fluorescence for MBP $(\boldsymbol{A})$, NF $(\boldsymbol{B})$, and Sox10-GFP $(\boldsymbol{C})$, pooled from two experiments using a total of 15 slices for control and D-lactate, and 10 slices for L-lactate. $\boldsymbol{D}, \boldsymbol{E}$, Labeling intensity ratio of MBP/NF (D) and MBP/ Sox 10 -GFP $(\boldsymbol{E})$ in the same slices as $\boldsymbol{A}-\boldsymbol{C}$. $\boldsymbol{F}$, Images of the cerebral cortex in cultured brain slices from mice in which oligodendrocyte lineage cells express GFP under control of the Sox10 promoter. The slices were cultured in solution containing (from left to right) $41.5 \mathrm{~mm}$ glucose, $2.9 \mathrm{~mm}$ glucose, $2.9 \mathrm{~mm}$ glucose with $20 \mathrm{~mm}$ D-lactate, or $2.9 \mathrm{~mm}$ glucose with $20 \mathrm{~mm}$ L-lactate. Slices were immunolabeled for MBP (red) and NF (blue). Sox 10 -GFP is green. $\mathbf{G}-\boldsymbol{I}$, Normalized fluorescence for $\mathrm{MBP}(\boldsymbol{G}), \mathrm{NF}(\boldsymbol{H})$, and Sox10-GFP $(\boldsymbol{I})$, pooled from two separate experiments, using a total of 11 slices for $41.5 \mathrm{~mm}$ glucose, and 13 slices for each condition in $2.9 \mathrm{~mm}$ glucose. $\boldsymbol{J}, \boldsymbol{K}$, Labeling intensity ratio of MBP/NF200 $(\boldsymbol{J})$ and MBP/Sox10-GFP $(\boldsymbol{K})$ in the same slices as $\boldsymbol{G}-\boldsymbol{I}$. Error bars indicate SEM.

L-lactate compared with both the high-glucose and the lowglucose controls ( $p=6 \times 10^{-4}$ and 0.019 , respectively) (Fig. $6 \mathrm{~K})$, implying that there was an increase in myelination per oligodendrocyte lineage cell.

D-Lactate does not affect oligodendrocyte development and myelination

D-Lactate is taken up through MCTs and competes for uptake with L-lactate (Tekkök et al., 2005), although the lower affinity of
MCTs for D-lactate than L-lactate (Poole et al., 1990; Wang et al., 1993 ) implies that $20 \mathrm{~mm}$ D-lactate should inhibit uptake of low levels of endogenous L-lactate by only $\sim 25 \%$. D-Lactate cannot be efficiently metabolized by the mammalian brain (Gibbs and Hertz, 2008) and so might be expected to have no beneficial effect on myelination. At $41.5 \mathrm{~mm}$ glucose, $20 \mathrm{~mm}$ D-lactate had no effect on MBP, NF, or Sox10-GFP labeling (Fig. 6A-E), implying that D-lactate did not influence myelination, nor the number of 
axons or oligodendrocyte lineage cells. At $2.9 \mathrm{~mm}$ glucose, D-lactate also had no significant effect on any of the labeling parameters (Fig. $6 F-K$ ). Thus, the beneficial effect of L-lactate on myelination is specific to the physiological form of lactate.

\section{Discussion}

Energy deprivation often causes white matter damage, as in periventricular leukomalacia, stroke, and the secondary ischemia associated with spinal cord injury, but the preferred substrates for energy production and myelination by oligodendrocytes have not been identified. Here, we show that white matter oligodendrocytes can take up lactate through MCTs and that lactate can support the survival of oligodendrocyte lineage cells and myelination in low-glucose conditions. An overview of the fluxes of lactate between blood vessels, astrocytes, neurons, and oligodendrocytes is given in Figure 7.

Application of $10 \mathrm{~mm}$ lactate to acute brain slices generated an acidification in cells in the white matter, which was reduced by the MCT inhibitors phloretin, NPPB and 4-CIN, suggesting uptake of lactate through MCTs (Figs. 1-3). The lactate response in the white matter occurred both in cell bodies and in processes aligned with axons, presumed to be oligodendrocyte processes. Lactate uptake into oligodendrocytes was confirmed at the single-cell level by measuring the intracellular $\mathrm{pH}$ of single oligodendrocytes loaded with the $\mathrm{pH}$-sensitive dye by patch clamping (Fig. 3E). Immunolabeling at the light and EM level showed expression of MCT1 in myelin (Fig. 4), which presumably mediates lactate uptake into oligodendrocytes. The MCT1 labeling is in agreement with strong MCT1 mRNA expression in white matter areas of mouse brain and in oligodendrocyte lineage cells (KoehlerStec et al., 1998; Cahoy et al., 2008).

Normally, oligodendrocytes may take up extracellular lactate released from astrocytes (Fig. 7). It has been suggested that white matter astrocytes in the optic nerve can release lactate generated from metabolized glycogen, because blocking breakdown of glycogen (which is only present in astrocytes) or inhibiting lactate transport accelerates the loss of the compound action potential during aglycemic conditions (Wender et al., 2000; Brown et al., 2005). This was interpreted in terms of the astrocytes providing metabolic support to axons, but since oligodendrocytes become damaged in low-energy situations (Salter and Fern, 2005; Micu et al., 2006) it is possible that the lactate released from astrocytes also maintains the health of oligodendrocytes. Recently, Vinet et al. (2010) showed that oligodendrocytes can also be in direct contact with blood vessels, with no intervening astrocytic processes, suggesting that oligodendrocytes could also take up lactate and other substrates directly from the blood through endothelial cells.

In organotypic slice cultures, myelination and the number of oligodendrocyte lineage cells were gradually reduced as the glucose concentration was lowered (Fig. 5). Compared with $41.5 \mathrm{~mm}$ glucose, at $5.5 \mathrm{~mm}$ glucose the number of oligodendrocyte lineage cells and the level of myelin basic protein were significantly reduced. In contrast, the number of axons, as assessed by neurofila- ment labeling, was not decreased until the glucose concentration was lowered to $1.4 \mathrm{~mm}$. Thus, survival of oligodendrocyte lineage cells and the myelination they perform is more dependent on having an adequate glucose level than is neuronal survival.

Glucose concentrations $\sim 41.5 \mathrm{~mm}$ are commonly used for organotypic cultures (Stoppini et al., 1991; De Simoni and Yu, 2006) but represent hyperglycemic conditions and are far away from physiological values: normal brain extracellular glucose concentrations are $\sim 1 \mathrm{~mm}$ (McNay and Gold, 1999) or lower (Fray et al., 1997; Lowry et al., 1998). However, these high glucose concentrations are those present initially in the culture medium, and the actual glucose level will fall as glucose is used by the cells. Measurements of glucose uptake into rat organotypic hippocampal slices (Gramsbergen et al., 2003) showed that slices cultured in 5,2 , and $1 \mathrm{~mm}$ glucose used $0.36,0.27$, and $0.16 \mathrm{nmol}$ of glucose, respectively, per slice per minute. This corresponds to $1.56,1.17$, and $0.69 \mu \mathrm{mol}$ over the $3 \mathrm{~d}$ between medium changes in our experiments. Thus, if our organotypic cortical slices consume glucose at the same rate, for slices cultured in $1 \mathrm{ml}$ of solution containing 5.5, 2.9, or $1.4 \mathrm{~mm}$ glucose, after $3 \mathrm{~d}$ the concentration of glucose in the medium would be $\sim 3.9,1.7$, or $0.7 \mathrm{~mm}$, respectively (using the estimated consumption rates for 5,2 , or $1 \mathrm{~mm}$ glucose, respectively), and these concentrations would be lower if our (probably larger) cortical slices consume more glucose than the hippocampal slices of Gramsbergen et al. (2003). In addition, because of the limited diffusion speed of glucose (Lund-Andersen and Kjeldsen, 1976), the extracellular glucose concentration is lower in the middle of the slice than at the surface [by $\sim 0.4 \mathrm{~mm}$ in a $300 \mu \mathrm{m}$ slice from calculations by Tekkök et al. (2002)].

These estimates suggest that the slices cultured in $1.4 \mathrm{~mm}$ glucose experienced true hypoglycemia, and, since the numbers used in the calculations are approximate and the glucose consumption measurements by Gramsbergen et al. (2003) were from a different preparation, they do not exclude the possibility that the slices in $2.9 \mathrm{~mm}$ glucose also experienced true hypoglycemia. Neverthe- 
less, since a reduction in myelin protein expression and number of oligodendrocyte lineage cells was seen when the glucose concentration was lowered to $5.5 \mathrm{~mm}$ (Fig. $5 B, D$ ), it is worth bearing in mind the possibilities that, first, glucose alone does not suffice to maximize myelination and, second, that the survival of oligodendrocyte lineage cells, even in physiological glucose concentrations, may also require additional energy and carbon sources such as lactate or pyruvate, particularly when they are carrying out myelination. Consistent with this, compared with neurons and astrocytes, oligodendrocytes have a relatively low expression of the glucose-processing enzyme hexokinase (Snyder and Wilson, 1983; Cahoy et al., 2008), suggesting a low glycolytic rate, and Saneto and de Vellis (1985) found that oligodendrocytes in culture depended on the supply of exogenous pyruvate, another monocarboxylate.

Between 41.5 and $2.9 \mathrm{~mm}$ glucose, the ratio of MBP/Sox10GFP fluorescence was unchanged (Fig. $5 F$ ). This implies that the "myelin protein expressed per oligodendrocyte lineage cell" stayed the same, and thus the inhibitory effect of a low glucose level on myelin protein production (Fig. $5 B$ ) must be explained by a reduction in the number of oligodendrocyte lineage cells (Fig. 5D). Sox10-GFP labels mature and immature oligodendrocytes and OPCs, and thus a reduction in Sox10-GFP labeling could reflect a loss of cells from all three developmental stages. Indeed, Yan and Rivkees (2005) showed that hypoglycemia reduces OPC proliferation and maturation in OPC cultures and reduces the density of myelinated fibers in cerebellar slice cultures. At $1.4 \mathrm{~mm}$ glucose, the MBP/Sox10-GFP ratio decreased (Fig. $5 F$ ), implying that the myelin made per oligodendrocyte lineage cell decreased as well as the number of oligodendrocyte lineage cells. Neurofilament fluorescence was unchanged between 41.5 and $2.9 \mathrm{~mm}$ glucose. Only at $1.4 \mathrm{~mm}$ glucose did we observe a reduction in the neurofilament fluorescence (Fig. $5 C$ ), but this was smaller than the reduction in myelination, as the $\mathrm{MBP} / \mathrm{NF}$ ratio was greatly reduced (Fig. $5 E$ ). Thus, oligodendrocytes and myelination are particularly vulnerable to energy deprivation (Pantoni et al., 1996).

At $2.9 \mathrm{~mm}$ glucose, $20 \mathrm{~mm}$ lactate rescued the myelination lost in slices cultured in $2.9 \mathrm{~mm}$ glucose alone and increased the number of oligodendrocyte lineage cells toward the level seen in high glucose concentrations (Fig. 6). This suggests that lactate is used by the oligodendrocyte lineage cells, although it does not rule out the possibility that lactate supports the oligodendrocytes indirectly, e.g., by being taken up into axons (Brown et al., 2003; Tekkök et al., 2005), and converted into another substance that supports myelination, for example NAA ( $N$-acetylaspartate) (Chakraborty et al., 2001), which can be transferred to oligodendrocytes and converted into aspartate and acetyl CoA for use in myelination (Baslow et al., 1999). Application of lactate increased the MBP/Sox10-GFP ratio to a value above that seen in the highglucose and low-glucose control media (Fig. $6 \mathrm{~K}$ ). This suggests that the myelination per oligodendrocyte lineage cell is increased and might indicate that lactate is preferred over glucose as a substrate for myelin production.

MCTs also transport other energy-providing substances such as pyruvate and $\beta$-hydroxybutyrate. In humans, the highest rate of myelination occurs between midgestation and the end of the second postnatal year (Gilles, 1976; Kinney et al., 1994), whereas the most rapid myelination in rats happens during suckling (Davison and Dobbing, 1966). In this period, the level of $\beta$-hydroxybutyrate in the blood is elevated (Hawkins et al., 1971; Snell and Walker, 1973; Foster and Bailey, 1976) and can contribute to the brain energy supply (Cremer and Heath, 1974;
Nehlig and Pereira de Vasconcelos, 1993). Thus, our findings suggest that, in addition to lactate, other MCT substrates like $\beta$-hydroxybutyrate could also support myelination in vivo.

\section{References}

Baslow MH, Suckow RF, Sapirstein V, Hungund BL (1999) Expression of aspartoacylase activity in cultured rat macroglial cells is limited to oligodendrocytes. J Mol Neurosci 13:47-53.

Bergersen L, Waerhaug O, Helm J, Thomas M, Laake P, Davies AJ, Wilson MC, Halestrap AP, Ottersen OP (2001) A novel postsynaptic density protein: the monocarboxylate transporter MCT2 is co-localized with delta-glutamate receptors in postsynaptic densities of parallel fiberPurkinje cell synapses. Exp Brain Res 136:523-534.

Bergersen LH (2007) Is lactate food for neurons? Comparison of monocarboxylate transporter subtypes in brain and muscle. Neuroscience 145: 11-19.

Bergersen LH, Storm-Mathisen J, Gundersen V (2008) Immunogold quantification of amino acids and proteins in complex subcellular compartments. Nat Protoc 3:144-152.

Bröer S, Schneider HP, Bröer A, Rahman B, Hamprecht B, Deitmer JW (1998) Characterization of the monocarboxylate transporter 1 expressed in Xenopus laevis oocytes by changes in cytosolic $\mathrm{pH}$. Biochem J 333:167-174.

Bröer S, Bröer A, Schneider HP, Stegen C, Halestrap AP, Deitmer JW (1999) Characterization of the high-affinity monocarboxylate transporter MCT2 in Xenopus laevis oocytes. Biochem J 341:529-535.

Brown AM, Tekkök SB, Ransom BR (2003) Glycogen regulation and functional role in mouse white matter. J Physiol 549:501-512.

Brown AM, Baltan Tekkök S, Ransom BR (2004) Energy transfer from astrocytes to axons: the role of CNS glycogen. Neurochem Int 45:529-536.

Brown AM, Sickmann HM, Fosgerau K, Lund TM, Schousboe A, Waagepetersen HS, Ransom BR (2005) Astrocyte glycogen metabolism is required for neural activity during aglycemia or intense stimulation in mouse white matter. J Neurosci Res 79:74-80.

Butz CE, McClelland GB, Brooks GA (2004) MCT1 confirmed in rat striated muscle mitochondria. J Appl Physiol 97:1059-1066.

Cahoy JD, Emery B, Kaushal A, Foo LC, Zamanian JL, Christopherson KS, Xing Y, Lubischer JL, Krieg PA, Krupenko SA, Thompson WJ, Barres BA (2008) A transcriptome database for astrocytes, neurons, and oligodendrocytes: a new resource for understanding brain development and function. J Neurosci 28:264-278.

Carpenter L, Halestrap AP (1994) The kinetics, substrate and inhibitor specificity of the lactate transporter of Ehrlich-Lettre tumour cells studied with the intracellular $\mathrm{pH}$ indicator BCECF. Biochem J 304:751-760.

Chakraborty G, Mekala P, Yahya D, Wu G, Ledeen RW (2001) Intraneuronal $N$-acetylaspartate supplies acetyl groups for myelin lipid synthesis: evidence for myelin-associated aspartoacylase. J Neurochem 78:736-745.

Chaudhry FA, Lehre KP, van Lookeren Campagne M, Ottersen OP, Danbolt NC, Storm-Mathisen J (1995) Glutamate transporters in glial plasma membranes: highly differentiated localizations revealed by quantitative ultrastructural immunocytochemistry. Neuron 15:711-720.

Cremer JE, Heath DF (1974) The estimation of rates of utilization of glucose and ketone bodies in the brain of the suckling rat using compartmental analysis of isotopic data. Biochem J 142:527-544.

Davison AN, Dobbing J (1966) Myelination as a vulnerable period in brain development. Br Med Bull 22:40-44.

De Simoni A, Yu LM (2006) Preparation of organotypic hippocampal slice cultures: interface method. Nat Protoc 1:1439-1445.

Dombrowski GJ Jr, Swiatek KR, Chao KL (1989) Lactate, 3-hydroxybutyrate, and glucose as substrates for the early postnatal rat brain. Neurochem Res 14:667-675.

Fern R, Möller T (2000) Rapid ischemic cell death in immature oligodendrocytes: a fatal glutamate release feedback loop. J Neurosci 20:34-42.

Follett PL, Rosenberg PA, Volpe JJ, Jensen FE (2000) NBQX attenuates excitotoxic injury in developing white matter. J Neurosci 20:9235-9241.

Foster PC, Bailey E (1976) Changes in hepatic fatty acid degradation and blood lipid and ketone body content during development of the rat. Enzyme 21:397-407.

Fray AE, Boutelle M, Fillenz M (1997) Extracellular glucose turnover in the striatum of unanaesthetized rats measured by quantitative microdialysis. J Physiol 504:721-726.

Fu Y, Sun W, Shi Y, Shi R, Cheng JX (2009) Glutamate excitotoxicity inflicts paranodal myelin splitting and retraction. PLoS One 4:e6705. 
Garcia CK, Brown MS, Pathak RK, Goldstein JL (1995) cDNA cloning of MCT2, a second monocarboxylate transporter expressed in different cells than MCT1. J Biol Chem 270:1843-1849.

Gibbs ME, Hertz L (2008) Inhibition of astrocytic energy metabolism by D-lactate exposure impairs memory. Neurochem Int 52:1012-1018.

Gilles FH (1976) Myelination in the neonatal brain. Hum Pathol 7:244-248.

Gramsbergen JB, Leegsma-Vogt G, Venema K, Noraberg J, Korf J (2003) Quantitative on-line monitoring of hippocampus glucose and lactate metabolism in organotypic cultures using biosensor technology. J Neurochem 85:399-408.

Halestrap AP, Meredith D (2004) The SLC16 gene family-from monocarboxylate transporters (MCTs) to aromatic amino acid transporters and beyond. Pflugers Arch 447:619-628.

Halestrap AP, Price NT (1999) The proton-linked monocarboxylate transporter (MCT) family: structure, function and regulation. Biochem J 343:281-299.

Hashimoto T, Hussien R, Cho HS, Kaufer D, Brooks GA (2008) Evidence for the mitochondrial lactate oxidation complex in rat neurons: demonstration of an essential component of brain lactate shuttles. PLoS One 3:e2915.

Hawkins RA, Williamson DH, Krebs HA (1971) Ketone-body utilization by adult and suckling rat brain in vivo. Biochem J 122:13-18.

Jackson VN, Price NT, Carpenter L, Halestrap AP (1997) Cloning of the monocarboxylate transporter isoform MCT2 from rat testis provides evidence that expression in tissues is species-specific and may involve posttranscriptional regulation. Biochem J 324:447-453.

Káradóttir R, Cavelier P, Bergersen LH, Attwell D (2005) NMDA receptors are expressed in oligodendrocytes and activated in ischaemia. Nature 438:1162-1166.

Káradóttir R, Hamilton NB, Bakiri Y, Attwell D (2008) Spiking and nonspiking classes of oligodendrocyte precursor glia in CNS white matter. Nat Neurosci 11:450-456.

Kessaris N, Fogarty M, Iannarelli P, Grist M, Wegner M, Richardson WD (2006) Competing waves of oligodendrocytes in the forebrain and postnatal elimination of an embryonic lineage. Nat Neurosci 9:173-179.

Kinney HC, Karthigasan J, Borenshteyn NI, Flax JD, Kirschner DA (1994) Myelination in the developing human brain: biochemical correlates. Neurochem Res 19:983-996.

Koeda T, Suganuma I, Kohno Y, Takamatsu T, Takeshita K (1990) MR imaging of spastic diplegia. Comparative study between preterm and term infants. Neuroradiology 32:187-190.

Koehler-Stec EM, Simpson IA, Vannucci SJ, Landschulz KT, Landschulz WH (1998) Monocarboxylate transporter expression in mouse brain. Am J Physiol 275:E516-E524.

Landsend AS, Amiry-Moghaddam M, Matsubara A, Bergersen L, Usami S, Wenthold RJ, Ottersen OP (1997) Differential localization of delta glutamate receptors in the rat cerebellum: coexpression with AMPA receptors in parallel fiber-spine synapses and absence from climbing fiberspine synapses. J Neurosci 17:834-842.

Li S, Mealing GA, Morley P, Stys PK (1999) Novel injury mechanism in anoxia and trauma of spinal cord white matter: glutamate release via reverse $\mathrm{Na}^{+}$-dependent glutamate transport. J Neurosci 19:RC16(1-9).

Lowry JP, O’Neill RD, Boutelle MG, Fillenz M (1998) Continuous monitoring of extracellular glucose concentrations in the striatum of freely moving rats with an implanted glucose biosensor. J Neurochem 70:391-396.

Lund-Andersen H, Kjeldsen CS (1976) Uptake of glucose analogues by rat brain cortex slices: a kinetic analysis based upon a model. J Neurochem 27:361-368.

Manning SM, Talos DM, Zhou C, Selip DB, Park HK, Park CJ, Volpe JJ, Jensen FE (2008) NMDA receptor blockade with memantine attenuates white matter injury in a rat model of periventricular leukomalacia. J Neurosci 28:6670-6678.

Manning Fox JE, Meredith D, Halestrap AP (2000) Characterisation of human monocarboxylate transporter 4 substantiates its role in lactic acid efflux from skeletal muscle. J Physiol 529:285-293.

McNay EC, Gold PE (1999) Extracellular glucose concentrations in the rat hippocampus measured by zero-net-flux: effects of microdialysis flow rate, strain, and age. J Neurochem 72:785-790.

Meredith D, Bell P, McClure B, Wilkins R (2002) Functional and molecular characterisation of lactic acid transport in bovine articular chondrocytes. Cell Physiol Biochem 12:227-234.
Micu I, Jiang Q, Coderre E, Ridsdale A, Zhang L, Woulfe J, Yin X, Trapp BD, McRory JE, Rehak R, Zamponi GW, Wang W, Stys PK (2006) NMDA receptors mediate calcium accumulation in myelin during chemical ischaemia. Nature 439:988-992.

Nehlig A, Pereira de Vasconcelos A (1993) Glucose and ketone body utilization by the brain of neonatal rats. Prog Neurobiol 40:163-221.

Pantoni L, Garcia JH, Gutierrez JA (1996) Cerebral white matter is highly vulnerable to ischemia. Stroke 27:1641-1646; discussion 1647.

Pellerin L, Pellegri G, Bittar PG, Charnay Y, Bouras C, Martin JL, Stella N, Magistretti PJ (1998) Evidence supporting the existence of an activitydependent astrocyte-neuron lactate shuttle. Dev Neurosci 20:291-299.

Philp NJ, Yoon H, Lombardi L (2001) Mouse MCT3 gene is expressed preferentially in retinal pigment and choroid plexus epithelia. Am J Physiol Cell Physiol 280:C1319-C1326.

Poole RC, Halestrap AP (1993) Transport of lactate and other monocarboxylates across mammalian plasma membranes. Am J Physiol 264:C761-C782.

Poole RC, Cranmer SL, Halestrap AP, Levi AJ (1990) Substrate and inhibitor specificity of monocarboxylate transport into heart cells and erythrocytes. Further evidence for the existence of two distinct carriers. Biochem J 269:827-829.

Poole RC, Sansom CE, Halestrap AP (1996) Studies of the membrane topology of the rat erythrocyte $\mathrm{H}^{+}$/lactate cotransporter (MCT1). Biochem J 320:817-824.

Rafiki A, Boulland JL, Halestrap AP, Ottersen OP, Bergersen L (2003) Highly differential expression of the monocarboxylate transporters MCT2 and MCT4 in the developing rat brain. Neuroscience 122:677-688.

Salter MG, Fern R (2005) NMDA receptors are expressed in developing oligodendrocyte processes and mediate injury. Nature 438:1167-1171.

Sánchez-Abarca LI, Tabernero A, Medina JM (2001) Oligodendrocytes use lactate as a source of energy and as a precursor of lipids. Glia 36:321-329.

Saneto RP, de Vellis J (1985) Characterization of cultured rat oligodendrocytes proliferating in a serum-free, chemically defined medium. Proc Natl Acad Sci U S A 82:3509-3513.

Snell K, Walker DG (1973) Glucose metabolism in the newborn rat. Temporal studies in vivo. Biochem J 132:739-752.

Snyder CD, Wilson JE (1983) Relative levels of hexokinase in isolated neuronal, astrocytic and oligodendroglial fractions from rat brain. J Neurochem 40:1178-1181.

Sokoloff L (1992) The brain as a chemical machine. Prog Brain Res 94:19-33.

Stoppini L, Buchs PA, Muller D (1991) A simple method for organotypic cultures of nervous tissue. J Neurosci Methods 37:173-182.

Tekkök SB, Godfraind JM, Krnjević K (2002) Moderate hypoglycemia aggravates effects of hypoxia in hippocampal slices from diabetic rats. Neuroscience 113:11-21.

Tekkök SB, Brown AM, Westenbroek R, Pellerin L, Ransom BR (2005) Transfer of glycogen-derived lactate from astrocytes to axons via specific monocarboxylate transporters supports mouse optic nerve activity. J Neurosci Res 81:644-652.

Vicario C, Medina JM (1992) Metabolism of lactate in the rat brain during the early neonatal period. J Neurochem 59:32-40.

Vicario C, Arizmendi C, Malloch G, Clark JB, Medina JM (1991) Lactate utilization by isolated cells from early neonatal rat brain. J Neurochem 57:1700-1707.

Vinet J, Lemieux P, Tamburri A, Tiesinga P, Scafidi J, Gallo V, Sík A (2010) Subclasses of oligodendrocytes populate the mouse hippocampus. Eur J Neurosci 31:425-438.

Wang X, Poole RC, Halestrap AP, Levi AJ (1993) Characterization of the inhibition by stilbene disulphonates and phloretin of lactate and pyruvate transport into rat and guinea-pig cardiac myocytes suggests the presence of two kinetically distinct carriers in heart cells. Biochem J 290:249-258.

Weiner ID, Hamm LL (1989) Use of fluorescent dye BCECF to measure intracellular pH in cortical collecting tubule. Am J Physiol 256:F957-F964.

Wender R, Brown AM, Fern R, Swanson RA, Farrell K, Ransom BR (2000) Astrocytic glycogen influences axon function and survival during glucose deprivation in central white matter. J Neurosci 20:6804-6810.

Wilson MC, Jackson VN, Heddle C, Price NT, Pilegaard H, Juel C, Bonen A, Montgomery I, Hutter OF, Halestrap AP (1998) Lactic acid efflux from white skeletal muscle is catalyzed by the monocarboxylate transporter isoform MCT3. J Biol Chem 273:15920-15926.

Yan H, Rivkees SA (2006) Hypoglycemia influences oligodendrocyte development and myelin formation. Neuroreport 17:55-59. 